\title{
Influence of Particle Shape on Microstructure and Magnetic Properties of Iron Powder Cores*
}

\author{
Takuya Takashita, Naomichi Nakamura and Yukiko Ozaki \\ JFE Steel Corporation, Steel Research Laboratory, Chiba 260-0835, Japan
}

The coercive force of an iron powder core decreases with an increase in the circularity of the base iron powder. Microstructural observation reveals that the crystal grain size of the iron powder core is reduced by recrystallization during stress relief annealing after powder compaction. An analysis of the work hardening behavior during the compaction process shows that a rounder particle shape leads to smaller particle deformation, resulting in a reduced grain refinement effect during recrystallization. A grain boundary pinning model convincingly describes the reduction of coercive force with the increase in the eventual grain size. [doi:10.2320/matertrans.M2016197]

(Received May 30, 2016; Accepted August 25, 2016; Published September 30, 2016)

Keywords: water atomized iron powder, iron powder core, iron loss, particle shape

\section{Introduction}

Iron powder cores are made from insulation-coated iron powders through a powder compaction process, and featurehigher saturation magnetic flux densities than those of conventional ferrite cores and lower eddy current losses lower than those of conventional metal magnetic materials such as electrical steel sheets ${ }^{1)}$. With these features, iron powder cores have been applied to devices such as reactors for hybrid vehicles ${ }^{2}$.

Soft magnetic metal powders such as pure iron, $\mathrm{Fe}-\mathrm{Si}$ or $\mathrm{Fe}-\mathrm{Si}$-Al are applied as raw materials for iron powder cores $^{3-5)}$. Among these materials, pure iron has the highest magnetic flux density. To expand the fields of application of pure iron powder cores, reduction of hysteresis loss is required.

One way to reduce hysteresis loss is to reduce the domain wall pinning force. Crystal grain boundaries, dislocations, and impurity atoms act as pinning sites ${ }^{6)}$. Annealing is an effective process for relieving the strain induced during the compaction process, and it leads to a reduction of coercive force and an eventual reduction of hysteresis loss.

Several studies have reported the coercive force of pure iron powder cores. Hojo et $\mathrm{al}^{7)}{ }^{7)}$ have reported that the coercive force of an iron powder core decreases with an increase in the annealing temperature up to $973 \mathrm{~K}$, but increases if the annealing temperature exceeds $973 \mathrm{~K}$. This phenomenon is attributed to crystal grain size refinement due to recrystallization. Maeda et al. ${ }^{8)}$ have reported that both hysteresis loss and eddy current loss decreases with spheroidizing of the iron powder particles.

Recrystallization is a process by which new dislocation free crystal grains are formed inside a deformed structure ${ }^{9)}$. It indicates that the particle deformation induced during the compaction process affects the microstructure after annealing.

The particle shape of the base iron powder influences the number and distribution of the contact points between particles, and also influences the particle deformation induced

*This Paper was Originally Published in Japanese in J. Japan Inst. Met. Mater. 79 (2015) 315-323. during the compaction process. The amount of particle deformation affects the recrystallization behavior during the annealing process after compaction, leading to an influence on the microstructure of the powder core. However, few studies have been reported on the relationship between the powder particle shape and the amount of compaction strain, or its influence on the effect of annealing on the microstructure and coercive force of powder cores.

In this study, we investigated the influence of the powder particle shape on the microstructure and coercive force quantitatively, and found that the crystal grain size in an iron powder core increases with an increase in the circularity of the powder particle. The mechanism and effect on the coercive force will be discussed in detail.

\section{Experiment}

\subsection{Base iron powders}

The preparation process of the base iron powders is shown in Fig. 1. Molten steel was water atomized to form an iron powder. The atomizing conditions such as the water pressure, flow rate, etc. were controlled to modify the circularity of the powder particle. The iron powders were annealed at $1223 \mathrm{~K}$ for $3.6 \mathrm{ks}$ in a hydrogen atmosphere. The particle size distribution of the annealed powders was controlled by the sieving and remixing process so as to be mutually equivalent.

The chemical compositions of the three base iron powders are shown Table 1. The major impurities are $\mathrm{O}, \mathrm{Si}$ and $\mathrm{Mn}$. The difference of the total impurity amount among these three powders is 0.017 mass\% at the largest. This is within the range of scattering over repetition with the same atomizing conditions. As discussed later, the influence of such an impurity difference on the coercive force is smaller than that of the difference in the particle circularity.

The apparent density $\left(D_{\mathrm{A}}\right)$ and particle size distribution were measured according to JIS Z 2504 and JIS Z 2510, respectively. The mass average particle size $D_{50}$ was determined at the point of $50 \%$ on the accumulative particle size distribution. The powder properties of the three base iron powders are shown in Table 2. The average particle size $D_{50}$ and the particle size distribution are essentially equivalent. The apparent density of these powders varies from $3.19 \mathrm{Mg} \mathrm{m}^{-3}$ (powder 
Table 1 Chemical composition.

\begin{tabular}{ccccccccccccc}
\hline \multicolumn{10}{c}{ (mass\%) } \\
\hline Base iron powder & $\mathrm{C}$ & $\mathrm{O}$ & $\mathrm{N}$ & $\mathrm{Si}$ & $\mathrm{Mn}$ & $\mathrm{P}$ & $\mathrm{S}$ & $\mathrm{Cr}$ & $\mathrm{Ni}$ & $\mathrm{Al}$ & $\mathrm{Fe}$ & Total impurity \\
\hline $\mathrm{A}$ & 0.0020 & 0.0690 & 0.0005 & 0.0200 & 0.0430 & 0.0090 & 0.0004 & 0.0080 & 0.0090 & 0.0030 & Bal. & 0.164 \\
$\mathrm{~B}$ & 0.0043 & 0.0673 & 0.0005 & 0.0170 & 0.0400 & 0.0090 & 0.0004 & 0.0080 & 0.0200 & 0.0030 & Bal. & 0.170 \\
$\mathrm{C}$ & 0.0033 & 0.0539 & 0.0010 & $<0.0080$ & 0.0520 & 0.0020 & 0.0002 & 0.0180 & 0.0200 & 0.0030 & Bal. & 0.153 \\
\hline
\end{tabular}

Table 2 Powder properties.

\begin{tabular}{|c|c|c|c|c|c|c|c|c|c|}
\hline \multirow[b]{2}{*}{$\begin{array}{l}\text { Base iron } \\
\text { powder }\end{array}$} & \multicolumn{6}{|c|}{ Particle size distribution (mass\%) } & \multirow[b]{2}{*}{$\begin{array}{l}\text { Mean diameter, } \\
D_{50} / \mu \mathrm{m}\end{array}$} & \multirow[b]{2}{*}{$\begin{array}{l}\text { Apparent density, } \\
D_{\mathrm{A}} / \mathrm{Mg} \mathrm{m}^{-3}\end{array}$} & \multirow[b]{2}{*}{$\begin{array}{l}\text { Powder circularity, } \\
\qquad C\end{array}$} \\
\hline & $\begin{array}{c}180 \sim 150 \\
\mu \mathrm{m}\end{array}$ & $\begin{array}{c}150 \sim 106 \\
\mu \mathrm{m}\end{array}$ & $\begin{array}{c}106 \sim 75 \\
\mu \mathrm{m}\end{array}$ & $\begin{array}{c}75 \sim 63 \\
\mu \mathrm{m}\end{array}$ & $\begin{array}{c}75 \sim 45 \\
\mu \mathrm{m}\end{array}$ & $\begin{array}{l}45 \sim \\
\mu \mathrm{m}\end{array}$ & & & \\
\hline A & 0.6 & 25.0 & 31.8 & 9.8 & 17.4 & 15.4 & 82.2 & 4.07 & 0.83 \\
\hline B & 0.1 & 23.5 & 32.8 & 8.4 & 17.2 & 18.0 & 81.0 & 3.57 & 0.77 \\
\hline $\mathrm{C}$ & 1.3 & 23.1 & 33.6 & 8.6 & 16.8 & 16.6 & 82.4 & 3.19 & 0.73 \\
\hline
\end{tabular}

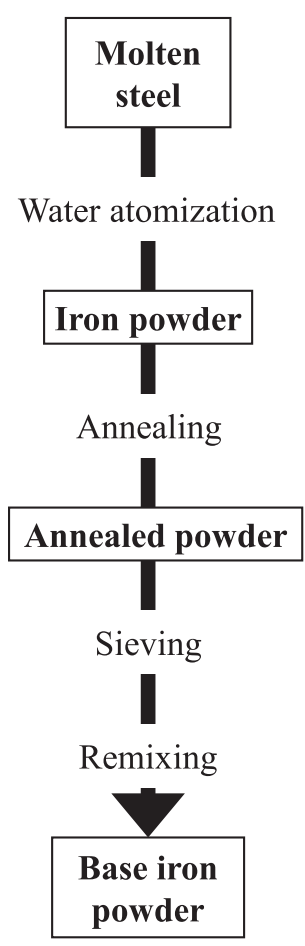

Fig. 1 Preparation process of base iron powders.

C) to $4.07 \mathrm{Mg} \mathrm{m}^{-3}$ (powder A). Apparent density is generally affected by the particle size distribution and particle shape, and a rounder particle shape gives a higher apparent density ${ }^{10)}$. In this research, the three base iron powders have the same particle size distribution. Hence, the apparent density should be mainly affected by the particle shape.

The particle shape of the base iron powders was observed by optical micrography. For this purpose, the powders were molded in a thermoplastic resin, polished and etched with natal. As shown in Fig. 2, powder A is almost circular, while powders $\mathrm{B}$ and $\mathrm{C}$ show significant irregularity.

The particle circularity of the base iron powders was quantified through an image analysis of the optical micrographs. The circularity of each particle is defined as $L_{\mathrm{c}} / L_{\mathrm{a}}$, where $L_{\mathrm{a}}$ is the periphery of the particle cross section and $L_{\mathrm{c}}$ is the pe-

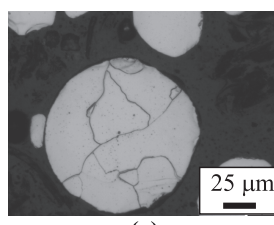

(a)

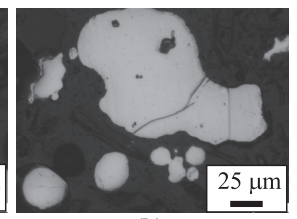

(b)

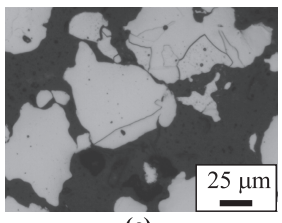

(c)
Fig. 2 Optical micrographs of cross section of base powder particles, (a) Powder A, (b) Powder B, (c) Powder C.

riphery of a perfect circle with the same area. This is unity if the particle cross section is a perfect circle, and decreases with an increase in shape irregularity. The software program Image J (Public domain, National Institutes of Health) was used to calculate the circularity of each particle, and the average of the particles with diameters of $10 \mu \mathrm{m}$ or more was defined as "powder circularity" $C$. Because higher $\mathrm{C}$ values indicate higher apparent density (Table 2), circularity $C$ will be used as a parameter of the iron powder particle shape in the discussion below.

\subsection{Preparation of iron powder cores}

Iron powder cores were prepared through a process shown in Fig. 3. First, the base iron powders were coated with a silicone resin (Dow Corning Toray, SR2400) for insulation. The base powders were mixed with the resin, which had been dissolved with a xylene-based organic solvent, and then dried at room temperature. The amount of the resin was adjusted to 0.25 mass $\%$ of the total mass of the coated iron powder. These powders were then heated to $473 \mathrm{~K}$ for $7.2 \mathrm{ks}$ to harden the resin.

The coated powders were compacted into ring-shaped cores (outer diameter: $38 \mathrm{~mm}$, inner diameter: $25 \mathrm{~mm}$, height: $6 \mathrm{~mm}$ ) with a compaction pressure of $980 \mathrm{MPa}$. To remove the strain induced during the compaction process, these as-compacted cores were annealed at $823 \mathrm{~K}$ or $973 \mathrm{~K}$ for $2.7 \mathrm{ks}$ in a nitrogen atmosphere. Similar annealing conditions have also been applied previously for the same purpose ${ }^{9)}$.

\subsection{Evaluation}

The properties of the base iron powders and iron powder 
cores evaluated in this study are summarized in Table 3.

For microstructural observation by optical micrography, each of the specimens was molded in a thermoplastic resin, polished and etched with nital for the evaluation. The cores were cut before molding to observe the cross section perpendicular to the circumference.

The crystal grain size was measured from the optical micrographs of the specimens by the intercept method ${ }^{11)}$. The average crystal grain size over 40 particles or more was defined as the crystal grain size for each of the base powders and annealed cores.

The Micro Vickers hardness of the polished specimens was measured at 5 points with a load of $0.245 \mathrm{~N}$. The average of the three points excluding the maximum and minimum values was used as the core hardness.

The crystal orientation distributions in the iron powder cores were evaluated as kernel average misorientation (KAM) maps ${ }^{12}$ ) by the SEM/EBSD (Scanning electron microscopy/ Electron back scattered diffraction) method. KAM is the average misorientation angle between kernels defined on the

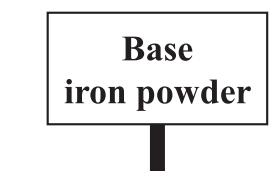

Silicone resin coating

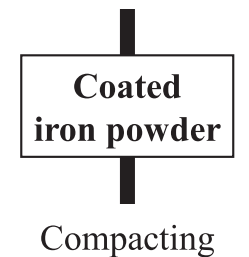

at room Temp., $980 \mathrm{MPa}$ in Air

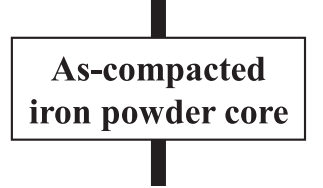

Annealing

at $823 \mathrm{~K} \sim 973 \mathrm{~K}$ for $2.7 \mathrm{ks}$ in $\mathrm{N}_{2}$

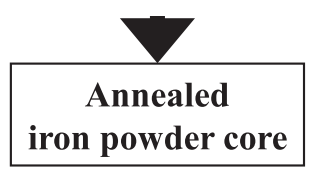

Fig. 3 Preparation process of iron powder cores. observation area, and the KAM map shows the dislocation density distribution ${ }^{12)}$. It should be noted that misorientation angles exceeding $5^{\circ}$ were excluded from the KAM calculation. The SEM/EBSD analysis was performed using a JEOL JSM-7001FA SEM and TSL OIM (orientation imaging microscopy) system. The observed area was $500 \mu \mathrm{m} \times 500 \mu \mathrm{m}$, and the electron beam irradiation step (i.e., the distance between the kernel centers) was $1 \mu \mathrm{m}$.

The direct current (DC) hysteresis loops of the annealedcores were measured with a DC magnetic properties measuring instrument (Metron, Inc. Type: SK-110). The densities and magnetic path lengths of the cores were calculated from their dimensions and weights. The primary and secondary coils comprised 100 and 40 turns, respectively, and were wound with $\phi 0.6 \mathrm{~mm}$ insulated copper wire. The maximum magnetic induction was adjusted to $1.0 \mathrm{~T}$ for all the measurements, and the coercive forces were evaluated from the measured hysteresis loops.

\section{Results}

The relationship between the circularity of the base iron powders and the green density of the as-compacted cores is shown in Fig. 4. The core density is within a range of $7.41 \pm$ $0.03 \mathrm{Mg} \mathrm{m}^{-3}$ and is regarded as independent of the powder circularity. The densities of the annealed cores are equivalent to those before annealing. The relationship between the powder circularity and coercive force $H_{\mathrm{c}}$ of the annealed cores is shown in Fig. 5. The cores annealed at $973 \mathrm{~K}$ shows lower $H_{\mathrm{c}}$ than those annealed at $873 \mathrm{~K} . H_{\mathrm{c}}$ of the $973 \mathrm{~K}$ annealed cores

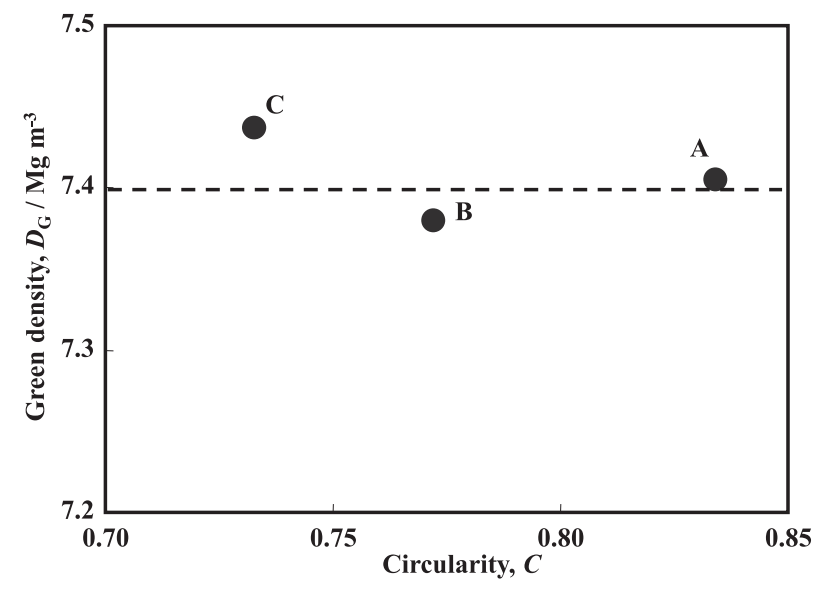

Fig. 4 Relationship between particle circularity and green density of as-compacted iron powder cores.

Table 3 Evaluated properties.

\begin{tabular}{|c|c|c|c|c|c|}
\hline & Microstructural observation & Crystal grain size & Micro-vikcers hardness & Crystal orientation & DC magnetic properties \\
\hline Base iron powders & $\bigcirc$ & $\bigcirc$ & $\bigcirc$ & - & - \\
\hline $\begin{array}{l}\text { Iron powder cores } \\
\text { (as-compacted) }\end{array}$ & $\bigcirc$ & - & $\bigcirc$ & $\bigcirc$ & - \\
\hline $\begin{array}{l}\text { Iron powder cores } \\
\text { (annealed at } 823 \mathrm{~K} \text { ) }\end{array}$ & $\bigcirc$ & $\bigcirc$ & $\bigcirc$ & $\bigcirc$ & $\bigcirc$ \\
\hline $\begin{array}{l}\text { Iron powder cores } \\
\text { (annealed at } 973 \mathrm{~K})\end{array}$ & $\bigcirc$ & $\bigcirc$ & $\bigcirc$ & $\bigcirc$ & $\bigcirc$ \\
\hline
\end{tabular}




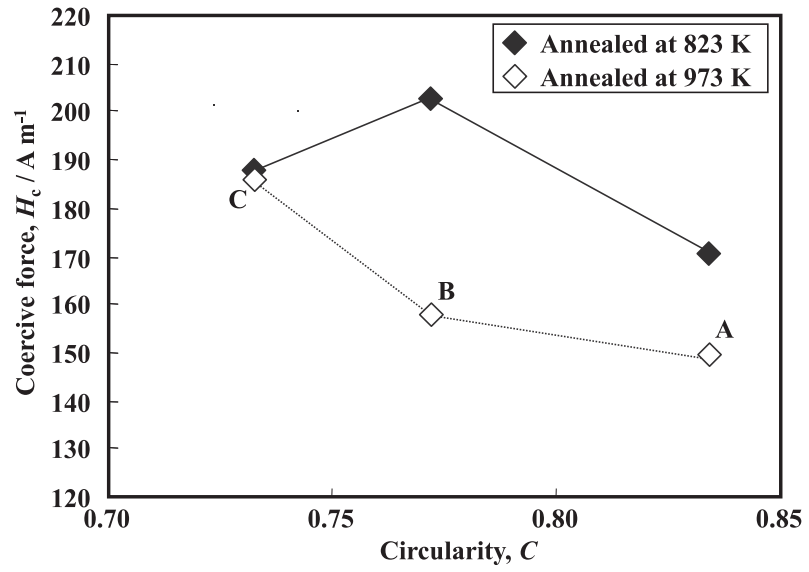

Fig. 5 Relationship between particle circularity and coercive force of annealed iron powder cores.

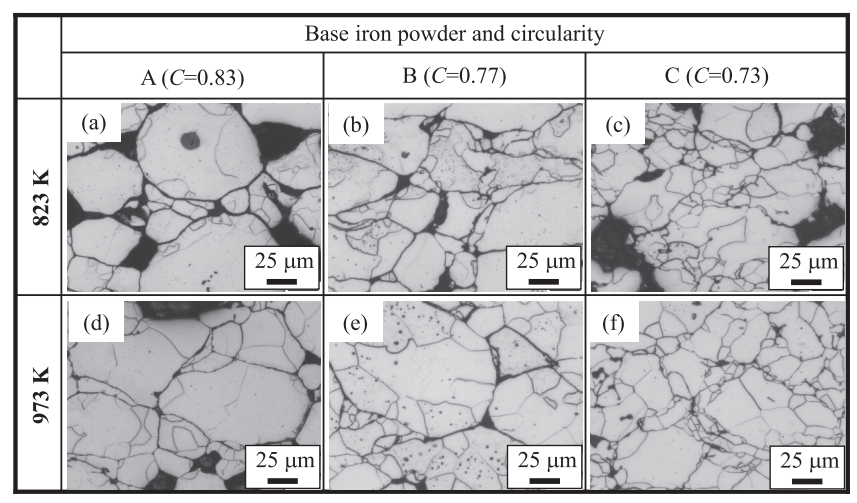

Fig. 6 Optical micrographs of iron powder cores annealed at $823 \mathrm{~K}$ and $973 \mathrm{~K}$.

decreases with an increase in the powder circularity, while that of the $823 \mathrm{~K}$ annealed cores shows a maximum at the circularity of 0.77

Optical micrographs of the annealed cores are shown in Fig. 6. The crystal grain size varies with the circularity of the base iron powder and the annealing temperature. The relationship between the circularity of the base iron powder and the crystal grain size is shown in Fig. 7. The crystal grain sizes of the annealed cores decrease with an increase in the circularity of the base iron powder. The crystal grain sizes of the base powders are around $40 \mu \mathrm{m}$, and are larger than that of the annealed cores. The crystal grain size of the as-compacted cores was not evaluated because of their complex etched pattern due to the dislocations induced by particle deformation during the compaction process.

The KAM maps of the as-compacted and annealed cores are shown in Fig. 8. In the as-compacted cores (Fig. 8 (a)(c)), the KAM values in the vicinity of the particle surfaces are higher than those in the inner area of the particle. The area with KAM values of $1^{\circ}$ or less increases with an increase in the annealing temperature, and becomes dominant after annealing at $973 \mathrm{~K}$ (Fig. 8(g)-(i)).

The $823 \mathrm{~K}$ annealed cores made from base iron powders $\mathrm{A}$ and B still show areas with KAM values over $1^{\circ}$ (Fig. 8(d), (e)). In the $823 \mathrm{~K}$ annealed core of powder $\mathrm{C}$, however, the area with KAM of $1^{\circ}$ or less is dominant.

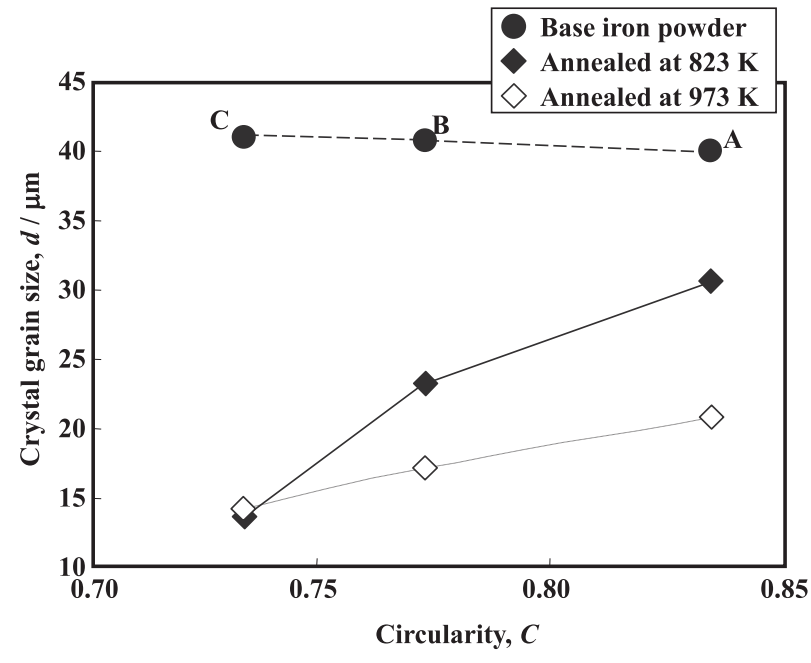

Fig. 7 Relationship between particle circularity and crystal grain size of annealed iron powder cores.

The hardnesses of the base iron powder, as-compacted cores and annealed cores are shown in Fig. 9. The as-compacted cores show the highest hardness, while the annealed cores shows hardness between these of the as-compacted cores and, the base iron powders, and the $823 \mathrm{~K}$ annealed cores display higher hardness than the $973 \mathrm{~K}$ annealed cores.

\section{Discussion}

\subsection{Effect of circularity of base iron powder on crystal grain size of annealed cores}

Magnified KAM maps of the cores made from base iron powder A are shown in Fig. 10. The as-compacted core shows areas with high ( $1^{\circ}$ or more) KAM values in the vicinity of the particle surfaces. On the other hand, in the $827 \mathrm{~K}$ annealed core, areas with low ( $1^{\circ}$ or less) KAM values are dominant and the crystal grain size in such areas is $5-20 \mu \mathrm{m}$, which is smaller than that of the base iron powder (about $40 \mu \mathrm{m}$ ). This indicates that crystal grain size refinement by recrystallization occurs during the compaction and annealing process.

In addition, the crystal grain size of the annealed cores increases with an increase in the powder circularity (Fig. 7). This indicates that an increase in the powder circularity reduces the amount of dislocations stored during compaction, because the recrystallized grain size increases with a decrease in dislocation density ${ }^{13}$.

In the following discussion, influence of the coated silicone resin on recrystallization behavior is regarded as negligible because the silicone resin is decomposed into stable Si ox$i^{2)}$ and carbon during the annealing process, whereas iron is not carburized even at the maximum annealing temperature of $973 \mathrm{~K}^{14-16)}$.

According to Ozaki et al. ${ }^{17)}$, the behavior of an iron powder bed during compaction is divided into two processes, "particle rearrangement" and "particle plastic deformation," and the porosity $V(p)$ of a powder bed at a pressure of $p$ is expressed as

$[V(0)-V(p)] / V(0)=a_{1} \cdot \exp \left(-b_{1} / p\right)+a_{2} \cdot \exp \left(-b_{2} / p\right)$,

The first and second terms of the right side of eq. (1) corre- 


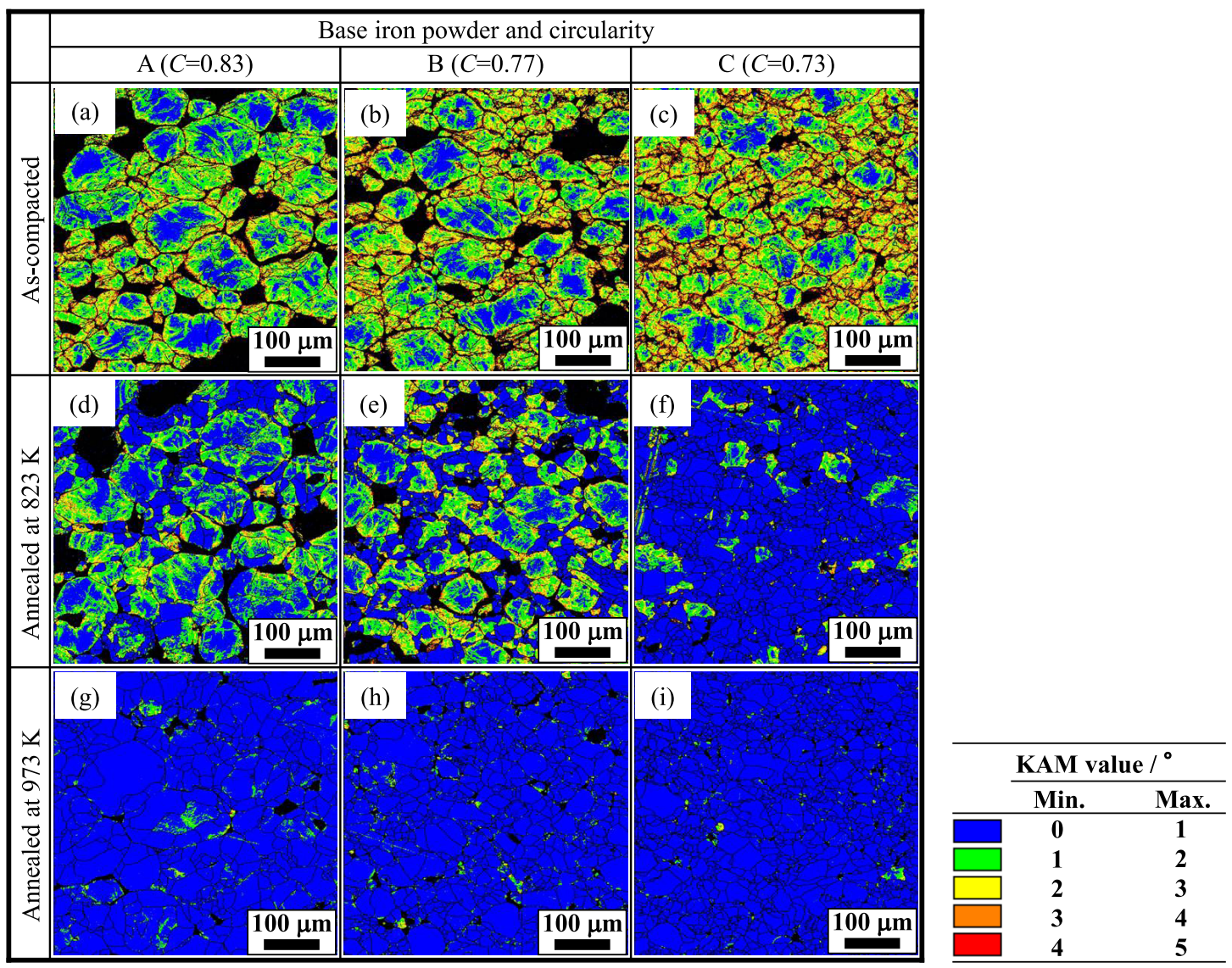

Fig. 8 KAM maps of iron powder cores.

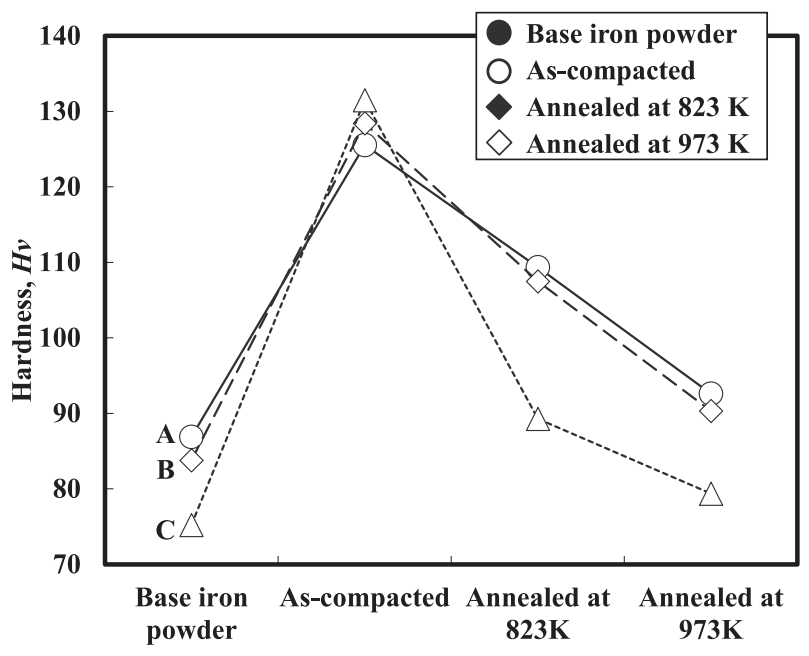

Fig. 9 Hardness of base iron powders, as-compacted cores and annealed cores.

spond to the contributions of "rearrangement" and "plastic deformation," respectively, $a_{1}, b_{1}, a_{2}$ and $b_{2}$ are the consolidation parameters depending on the composition, apparent density and compaction condition of the powder and $V(0)$ is the porosity before compaction.

Equation (1) can be rewritten with the apparent density $D_{\mathrm{A}}$, green density $D_{\mathrm{G}}$ and true density of the powder $D_{\mathrm{T}}$ as
$D_{\mathrm{G}}-D_{\mathrm{A}}=\left(D_{\mathrm{T}}-D_{\mathrm{A}}\right) \cdot\left[a_{1} \cdot \exp \left(-b_{1} / p\right)+a_{2} \cdot \exp \left(-b_{2} / p\right)\right]$,

where the left side corresponds to the amount of increase in the density of the powder bed from the start to finish of compaction.

The right side of eq. (2) is divided into two terms:

$$
\begin{aligned}
& \Delta D_{\mathrm{r}}=\left(D_{\mathrm{T}}-D_{\mathrm{A}}\right) \cdot a_{1} \cdot \exp \left(-b_{1} / p\right), \\
& \Delta D_{\mathrm{p}}=\left(D_{\mathrm{T}}-D_{\mathrm{A}}\right) \cdot a_{2} \cdot \exp \left(-b_{2} / p\right),
\end{aligned}
$$

where $\Delta D_{\mathrm{r}}$ and $\Delta D_{\mathrm{p}}$ correspond to the density increases due to "particle rearrangement" and "particle plastic deformation," respectively.

The consolidation parameters, $a_{1}, b_{1}, a_{2}$ and $b_{2}$ were determined as follows: First, a linear formula of each of the parameters as a function of $D_{\mathrm{A}}$ was derived through a regression analysis for the data given in Ref. 17). Second, the consolidation parameters of the three base iron powders were calculated by applying their apparent densities $D_{\mathrm{A}}$ to the regression formulas. The calculated parameters are shown in Table 4. If the true density $D_{\mathrm{T}}$ of pure iron is given as $7.87 \mathrm{Mg} \mathrm{m}^{-318)}$, $\Delta D_{\mathrm{p}}$ is calculated from eq. (4) with the parameters in Table 4.

The relationship between the circularity of the base iron powder and $\Delta D_{\mathrm{p}}$ is shown in Fig. 11 . The value of $\Delta D_{\mathrm{p}}$ decreases with an increase in the circularity of the base iron powder. This indicates that the plastic deformation of the iron powder during compaction decreases as the circularity of the base iron powder increases. 


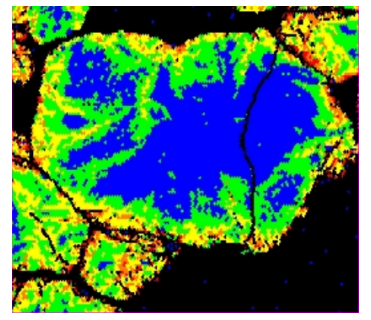

(a)

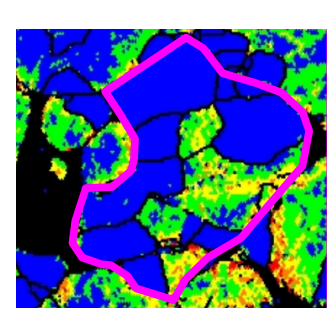

(b)

\begin{tabular}{cc}
\hline \multicolumn{2}{c}{ KAM value ${ }^{\rho}$} \\
\cline { 2 - 3 } Min. & Max. \\
\hline \\
\hline \\
\hline \\
\hline \\
\hline \\
\hline \\
\hline \\
\hline
\end{tabular}

$25 \mu \mathrm{m}$

Fig. 10 Magnified KAM maps of iron powder cores with base iron powder A, (a) As-compacted, (b) Core annealed at $823 \mathrm{~K}$.

Table 4 Parameters for compaction model.

\begin{tabular}{|c|c|c|c|c|c|c|}
\hline \multirow{2}{*}{$\begin{array}{l}\text { Base iron } \\
\text { powder }\end{array}$} & \multirow{2}{*}{$\begin{array}{c}\text { Apparent } \\
\text { Density, } \\
D_{\mathrm{A}} / \mathrm{Mg} \mathrm{m}^{-3}\end{array}$} & \multicolumn{4}{|c|}{ Parameters } & \multirow[b]{2}{*}{ Remark } \\
\hline & & $a_{1}$ & $b_{1}$ & $a_{2}$ & $b_{2}$ & \\
\hline - & 3.07 & 0.333 & 17.8 & 0.766 & 226 & \multirow{2}{*}{ Ref. 21) } \\
\hline - & 3.95 & 0.343 & 19.6 & 0.794 & 247 & \\
\hline A & 4.07 & 0.344 & 19.9 & 0.798 & 250 & \multirow{3}{*}{$\begin{array}{l}\text { Calculated } \\
\text { from regression }\end{array}$} \\
\hline B & 3.57 & 0.339 & 18.8 & 0.782 & 238 & \\
\hline $\mathrm{C}$ & 3.19 & 0.334 & 18.0 & 0.769 & 228 & \\
\hline
\end{tabular}

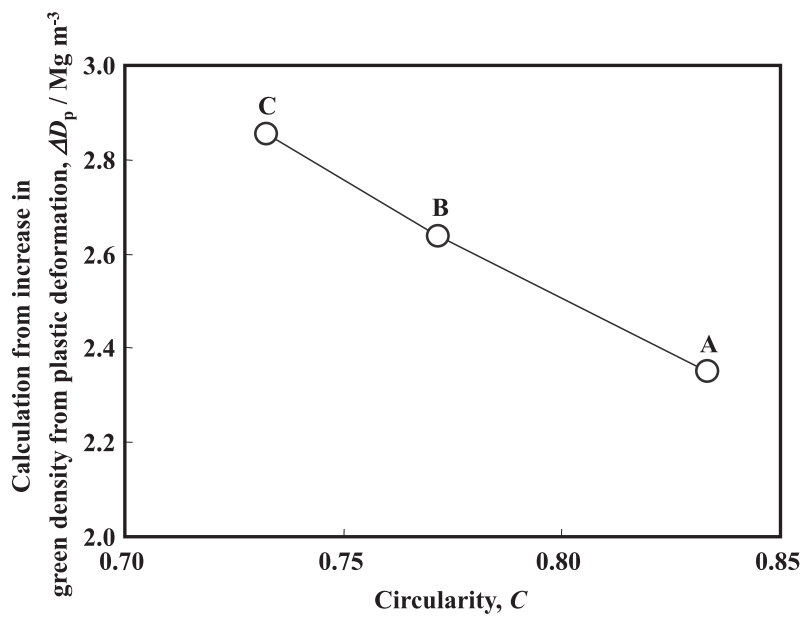

Fig. 11 Relationship between particle circularity and results of calculation of increase in green density from plastic deformation of iron powder particles.

The insulation layer would also affect the plastic deformation of the powder particles. However, the thickness of the particle insulation layer is estimated as approximately $0.2 \mu \mathrm{m}$ under the assumption that the particle is spherical. Since this is two orders of magnitude smaller than the average particle size of the base iron powders, the effect of the insulation layer is neglected in this discussion.

Next, the relationship between the crystal grain size and stored strain energy is discussed. As shown in the appendix, the strain under a uniaxial compaction process $\varepsilon_{\mathrm{p}}$ is given as

$$
\varepsilon_{\mathrm{p}}=\Delta D_{\mathrm{p}} / D_{\mathrm{G}},
$$

$\varepsilon_{\mathrm{p}}$ calculated as shown in Table 5 with $\Delta D_{\mathrm{p}}$ and $\Delta D_{\mathrm{G}}$ for each of the base iron powders.

Syarif et $a l .{ }^{19)}$ have reported the dislocation density of
Table 5 Strain values estimated from eq. (5).

\begin{tabular}{cc}
\hline Base iron powder & $\begin{array}{c}\text { Strain induced by plastic } \\
\text { deformation of iron powder, } \varepsilon_{\mathrm{p}}\end{array}$ \\
\hline A & 0.31 \\
B & 0.35 \\
C & 0.38 \\
\hline
\end{tabular}

cold-rolled pure iron sheets as a function of rolling reduction. Then, the dislocation density in the uniaxially compacted iron powder cores can be estimated from Ref. 19) by replacing rolling reduction with uniaxial strain $\varepsilon_{\mathrm{p}}{ }^{20}$. The smallest and largest values of the dislocation density estimated from the strain $\varepsilon_{\mathrm{p}}$ are $1.4 \times 10^{14} \mathrm{~m}^{-1}$ for powder $\mathrm{A}$ and $1.9 \times 10^{14} \mathrm{~m}^{-1}$ for powder $\mathrm{C}$, respectively.

Dislocation density is also estimated from the work hardening of the iron powder. Bailey and Hirsch ${ }^{21)}$ have given the increase in yield stress $\Delta \sigma$ resulting from the work hardening process as

$$
\Delta \sigma=\alpha G b \sqrt{\rho},
$$

where $G$ is the shear modulus (pure iron: $80 \mathrm{GPa}^{22)}$ ), $b$ is the Burgers vector (pure iron: $2.5 \times 10^{-10} \mathrm{~m}^{23)}$ ), $\rho$ is the dislocation density induced during the work hardening process, and $\alpha$ is a constant depending on the line tension and dislocation distribution. Nakashima et al. ${ }^{24)}$ reported $\alpha$ as 0.6.

To estimate $\Delta \sigma$ of the base iron powders, the following relationship between the Vickers hardness and yield stress ${ }^{25)}$ is applied.

$$
\sigma=3 H_{\mathrm{v}}
$$

This is differentiated as

$$
\Delta \sigma=3 \Delta H_{\mathrm{v}} .
$$

where $\Delta H_{\mathrm{v}}$ is the increase in hardness after plastic deformation of the iron powder. From eqs. (6) and (8), the relationship between $\Delta H_{\mathrm{v}}$ and $\rho$ is given as

$$
\rho=\left(3 \Delta H_{v} / \alpha G b\right)^{2} .
$$

The dislocation densities of the as-compacted and annealed cores are calculated from the hardness given in Fig. 9 by using this equation.

The relationship between the circularity of the base iron powders and the dislocation density of the iron powder cores is shown in Fig. 12. The dislocation density of the as-compacted cores increases with a decrease in circularity, and the 


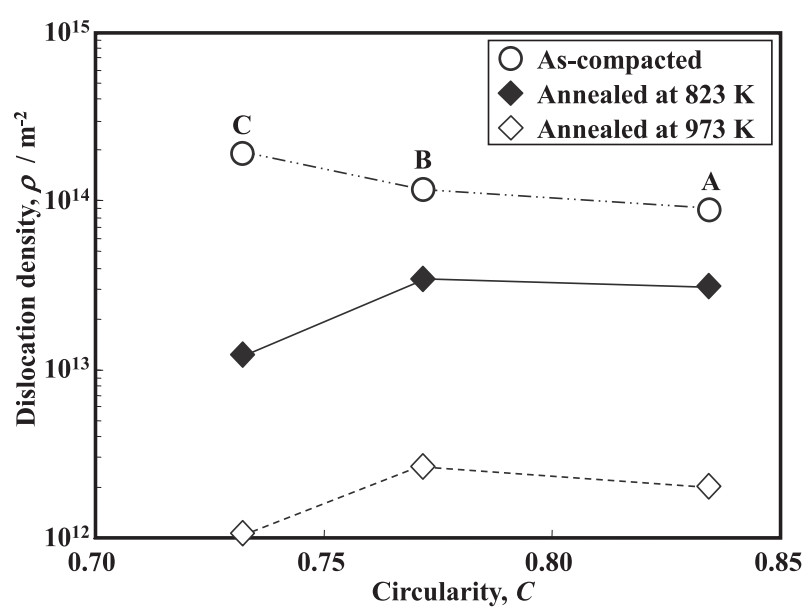

Fig. 12 Relationship between particle circularity and dislocation density within the iron powder cores.

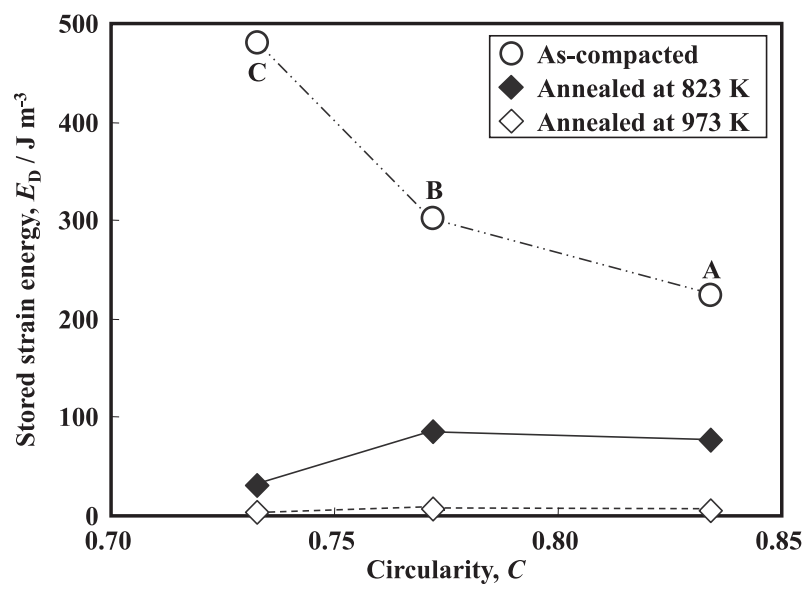

Fig. 13 Relationship between particle circularity and strain energy stored in iron powder cores

smallest and largest values of the dislocation density calculated from the hardness are $9.3 \times 10^{13} \mathrm{~m}^{-1}$ and $2.0 \times 10^{14} \mathrm{~m}^{-1}$, respectively. This range is in good agreement with that estimated from the particle plastic deformation model.

The dislocation density of the base iron powders are assumed to be the same because the powders were prepared through the same thermomechanical process, indicating that the plastic deformation of iron powders during compaction decreases with an increase in circularity.

The dislocation density of the annealed cores is also shown in Fig. 12 as a function of temperature. The dislocation density of the annealed cores is lower than that of the as-compacted cores. This indicates that strain energy was decreased by recrystallization.

The strain energy $E_{\mathrm{D}}$ is given as a function of dislocation density $\rho$ as

$$
E_{\mathrm{D}}=\rho G b^{2} / 2^{26)},
$$

and is estimated as a function of circularity as shown in Fig. 13. The strain energy of the as-compacted cores is higher than that of the annealed cores. Furthermore, the $E_{\mathrm{D}}$ of the $973 \mathrm{~K}$ annealed cores is lower than that of the $823 \mathrm{~K}$ annealed cores. This indicates that strain decreases with an increase in

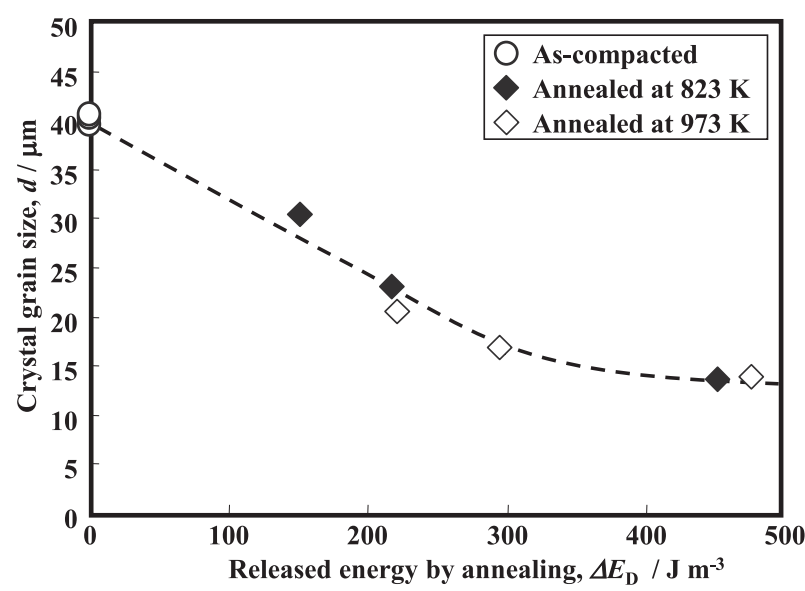

Fig. 14 Relationship between energy released by annealing and crysta grain size in iron powder cores (The dashed line is a visual guide line).

the annealing temperature.

The amount of the decrease in the strain energy by annealing, $\Delta E_{\mathrm{D}}$, is regarded as the difference of the strain energy between the as-compacted and annealed cores. The relationship between the crystal grain size and $\Delta E_{\mathrm{D}}$ of the iron powder cores is shown in Fig. 14. Here, the crystal grain sizes of the as-compacted cores are assumed to be the same as those of the base iron powders. The crystal grain size decreases with an increase in $\Delta E_{\mathrm{D}}$, and shows a universal behavior regardless of the base iron powder circularity and annealing temperature.

The $\Delta E_{\mathrm{D}}$ value would include the contribution of recrystallization and recovery. The crystal grain size after annealing decreases with an increase in the number of recrystallization nuclei, and the number of nuclei increases with an increase in $\Delta E_{\mathrm{D}}$. In Fig. $14, \Delta E_{\mathrm{D}}$ is related only to the crystal grain size, which is determined by the number of recrystallization nuclei. Thus, in this research, the amount of the decrease in strain energy by recovery is considered to be very small or the same in every annealed core.

From the above discussion, it is concluded that "particle plastic deformation" during the compaction process decreases with an increase in the circularity of the base iron powder, and that decrease causes a decrease in $\Delta E_{\mathrm{D}}$ in the as-compacted cores, resulting in an increase in the recrystallized crystal grain size after annealing.

\subsection{Effect of circularity of iron powder on coercive force of annealed core}

The coercive force $H_{\mathrm{c}}$ is affected by crystal grain boundaries, inclusions and dislocations. These are considered to be the pinning sites of domain wall movement. Pfeifer et al. ${ }^{27)}$ have proposed a coercive force model as

$$
H_{\mathrm{c}}=H_{\mathrm{ck}}+H_{\mathrm{c} \_ \text {ex }},
$$

where $H_{\mathrm{ck}}$ and $H_{\mathrm{c} \_ \text {ex }}$ are the contributions of the crystal grain boundary and that of inclusions and dislocations, respectively. Mager ${ }^{28)}$ has given the relationship between $H_{\mathrm{ck}}$ and crystal grain size $d$ as

$$
H_{\mathrm{ck}}=(3 \cdot \gamma) /\left(J_{\mathrm{s}} \cdot d\right),
$$


where $\gamma$ is the domain wall energy and $J_{\mathrm{s}}$ is the saturation magnetization of the domains. The experimental results for $\mathrm{Ni}-\mathrm{Fe}^{27)}, \mathrm{Fe}-\mathrm{Si}^{29)}$ and $\mathrm{Co}-\mathrm{Fe}^{30)}$ systems have shown good agreement with this model.

A theoretical expression of the domain wall energy is given as

$$
\gamma=a \sqrt{A \cdot K}
$$

where $A$ is the stiffness constant, $K$ is the magnetic anisotropy constant and $a$ is a constant depending on the kind of domain wall $^{31)}$.

In the case of iron, $A$ and $K$ have been estimated as $1.49 \times$ $10^{-11} \mathrm{~J} \mathrm{~m}^{-132)}$ and $4.72 \times 10^{4} \mathrm{~J} \mathrm{~m}^{-333)}$, respectively. In the case of iron, there are basically two kinds of domain walls with the angle between the spins on the two sides of $90^{\circ}$ and $180^{\circ}$. The constant $a$ for the $90^{\circ}$ and $180^{\circ}$ domain walls are 1 and $2^{31)}$, respectively. From this, the $\gamma$ values are calculated by eq. (13) as $8.4 \times 10^{-3} \mathrm{~J} \mathrm{~m}^{-2}$ for $90^{\circ}$ and $1.7 \times 10^{-2} \mathrm{~J} \mathrm{~m}^{-2}$ for $180^{\circ}$. Because these kinds of domain walls co-exist in actual system ${ }^{34)}$, the magnetic domain wall energy of an iron powder core will be in the range of $8.4 \times 10^{-3}$ to $1.7 \times$ $10^{-2} \mathrm{~J} \mathrm{~m}^{-2}$.

From eqs. (11) and (12), the relationship between $H_{\mathrm{c}}$ and $d$ is given as

$$
H_{\mathrm{c}}=S / d+H_{\text {c_ex }},
$$

where

$$
S=(3 \cdot \gamma) / J_{S}
$$

Thus, there is a linear relationship between $H_{\mathrm{c}}$ and $d^{-1}$ if $H_{\text {c_ex }}$ is constant, and $\gamma$ is estimated from the slope $S$ as

$$
\gamma=\left(S \cdot J_{\mathrm{s}}\right) / 3 \text {. }
$$

In this study, $H_{\text {c_ex }}$ of the $973 \mathrm{~K}$ annealed cores is assumed to be constant because the $973 \mathrm{~K}$ annealed cores have the same $E_{\mathrm{D}}$ as seen in Fig. 13, and this indicates that the $973 \mathrm{~K}$ annealed cores also have the same dislocation density. In addition, according to Ref. 7), the difference of $H_{\mathrm{c}}$ caused by differences in the impurity levels in the three base powders (0.017 mass\% at the highest; see Table 1$)$ is only $3 \%$, and this difference is negligibly small compared with the difference of the coercive force of the annealed cores in this research.

The relationship between the inverse of the crystal grain size, $d^{-1}$, and coercive force is shown in Fig. 15. The coercive force linearly increases with an increase in $d^{-1}$, as predicted by eq. (14). The linear regression formula gives the slope $S$ as $1.59 \times 10^{3}$ and the intercept $H_{\mathrm{c} \text { ex }}$ as $70.9 \mathrm{~A} \mathrm{~m}^{-1}$. The domain wall energy $\gamma$ is calculated as $1.2 \times 10^{-2} \mathrm{~J} \mathrm{~m}^{-2}$ from eq. (16) with $J_{\mathrm{s}}=2.16 \mathrm{~T}$ for iron ${ }^{35)}$ and the $S$ value given above. This $\gamma$ value is in the range between those for the $90^{\circ}$ and $180^{\circ}$ domain walls. Therefore, the relationship between $H_{\mathrm{c}}$ and $1 / d$ of the $973 \mathrm{~K}$ annealed cores in Fig. 15 is convincingly explained by the model of eq. (14).

In the case of the $823 \mathrm{~K}$ annealed cores, there are no linear relationships between $H_{\mathrm{c}}$ and $d^{-1}$ (Fig. 15). This indicates that $H_{\text {c_ex }}$ is not constant because dislocations still remain in these cores, as seen in Fig. 12.

Thus, the coercive force behavior is fully explained by the change of the crystal grain size when $H_{\mathrm{c}_{-} \text {ex }}$ is constant. In this case, the coercive force decreases with an increase in the cir-

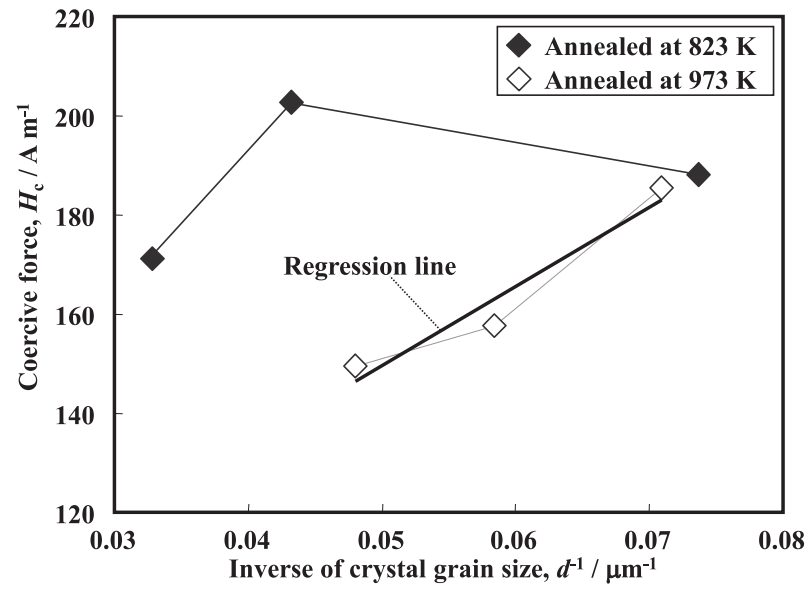

Fig. 15 Relationship between inverse of crystal grain size and coercive force.

cularity of base iron powder because of the crystal grain size growth associated with higher powder circularity.

\section{Conclusion}

Base iron powders with various circularities have been compacted and annealed into iron powder cores, and the influence of the powder circularity on the microstructure and magnetic properties of the cores have been investigated. The conclusions of this research are summarized as follows:

(1) The crystal grain size of the annealed core increases with an increase in the circularity of the base iron powder.

(2) Dislocations are mainly stored in the vicinity of the particle surface during compaction.

(3) The as-compacted cores are recrystallized from the particle surface during the annealing process.

(4) Model calculations show that the strain energy of the as-compacted cores increases with a decrease in the circularity of the base iron powder.

(5) This is attributed to an increase in the particle plastic deformation.

(6) Thus, an iron powder core made from a lower circularity powder display a larger number of recrystallization nuclei during annealing, which leads to a smaller crystal grain size after annealing.

(7) The strain energy of the iron powder cores annealed at $973 \mathrm{~K}$ is relieved to the same level regardless of the base iron powder circularity.

(8) As a result, the coercive force and the inverse of crystal grain size have a linear relationship, as predicted by a grain boundary pinning model.

(9) An increase in the circularity of the base iron powder suppresses "particle plastic deformation" during compaction, and this causes coarsening of the recrystallized grain size, leading to a decrease in coercive force.

\section{REFERENCES}

1) K. Sadahiro, S. Gotoh and S. Uenosono: JFE Tech. Rep. 8 (2005) 1-6.

2) M. Sugiyama, T. Yamaguchi, T. Ohkouchi, H. Kishimoto, T. Hattori and T. Saito: SOKEIZAI 51 (2010) 24-29. 
3) H. Mitani, A. Hanaki, H. Yaguchi and Y. Seki: Kobe Steel Eng. Rep. 48 (1998) 25-28.

4) S. Takemoto: Denki seiko 82 (2011) 57-65.

5) T. Ishimine, A. Watanabe, T. Ueno, T. Maeda and T. Tokuoka: SEI Tech. Rev. 72 (2011) 117-123.

6) T. Tokuoka, T. Maeda and T. Ishimine: SOKEIZAI 52 (2011) 11-18.

7) H. Hojo, N. Akagi, T. Sawayama and H. Mitani: Kobe Steel Eng. Rep. 60 (2010) 79-83.

8) T. Maeda, A. Sato, Y. Mochida, H. Toyoda, K. Mimura and T. Nishioka: Proc. Powder Metallurgy World Congress (Korean Powder Metallurgy Inst., 2006) pp. 1284-1285.

9) F. J. Humphrey and M. Hatherly: Recrystalization and related phenomena (Elsevier, 2004) p. 3.

10) The Japan Society of Powder and Powder Metallurgy: Funtaifunmatsuyakinyougojiten (Nikkan Kogyo Shinbun,2001) p. 541.

11) R.L. Fullman: Trans. Metall. AIME (1953) 197-447.

12) K. Sasaki, M. Kamaya, T. Miura and K. Fukuya: J. Jpn. Inst. Metals $\mathbf{7 4}$ (2010) 467-474.

13) F. J. Humphrey and M. Hatherly: Recrystallization and related phenomena (Elsevier, 2004) p. 224.

14) X. Zhang, R. Takahashi, T. Akiyama and J. Yagi: Tetsu-to-Hagane 83 (1997) 299-304.

15) T. Kameoka and T. Kimura: J. Jpn. Soc. Powder Powder Metallurgy 19 (1973) 281-285.

16) H. Mitani, K. Majima and Y. Hanatate: J. Jpn. Inst. Metals 39 (1975) 168-174.

17) Y. Ozaki, T. Ono, T. Takamiya and S. Uenosono: J. Jpn. Soc. Powder Powder Metallurgy 58 (2011) 83-90.

18) Randall M. Greman: Powder metallurgy (A Wiley-Interscience publication, 1998) p.4.

19) J. Syarif, K. Nakashima, T. Tsuchiyama and S. Takaki: Tetsu-to-Hagane 91 (2005) 790-795.

20) The Iron and Steel Institute of Japan: Theory and Practice of Flat Rolling (Reverse edition) (The Iron and Steel Institute of Japan,2010) p. 10

21) J.E. Bailey and P.B. Hirsch: Philos. Mag. 5 (1960) 485-497.

22) W. C. Leslie: The Physical Metallurgy of Steel (McGraw-Hill Kogakusha, 1982) p. 113.

23) W. C. Leslie: The Physical Metallurgy of Steel (McGraw-Hill Kogakusha, 1982) p. 3

24) K. Nakashima, Y. Fujimura, H. Matsubayashi, T. Tsuchiyama and S. Takaki: Tetsu-to-Hagane 93 (2007) 459-465.

25) T. Yoshizawa and G. Kuroki: Jour. Jpn. Soc. Mech. Eng. 64 (1961) 1453-1460.

26) F. J. Humphrey and M. Hatherly: Recrystallization and related phenomena (Elsevier, 2004) p. 18.

27) F. Pfeifer and C. Radeloff: J. Magn. Magn. Mater. 19 (1980) 190-207.

28) A. Mager: Annalen der Physik. 446 (1952) 15-16.

29) G. Herzer: IEEE Trans. Magn. 26 (1990) 1397-1402.

30) R.H. Yu, S. Basu, Y. Zhang, A. Parvizi-Majidi, and J.Q. Xiao: J. Appl Phys. 85 (1999) 6655-6659.

31) K. Ohta: JikikougakunokisoII (Kyoritsu Shuppan, 1973) pp. 272-273.

32) S. Chikazumi: Kyojiseitainobutsuri (last volume) (Shokabo, 1984) p. 175.

33) S. Chikazumi: Kyojiseitainobutsuri (last volume) (Shokabo, 1984) p. 4.

34) K. Ohta: JikikougakunokisoII (Kyoritsu Shuppan, 1973) p. 268.

35) K. Ohta: JikikougakunokisoII (Kyoritsu Shuppan, 1973) p. 275.

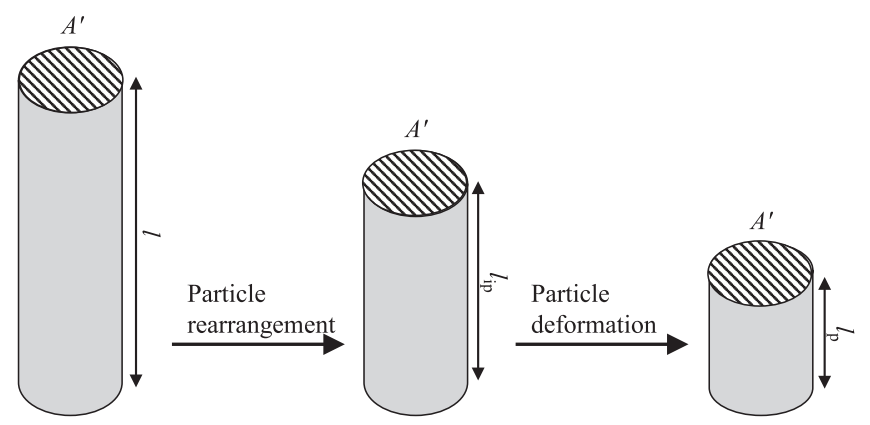

Fig. A1 Schema of compaction of iron powder.

\section{Appendix}

The schema of uniaxial compaction of an iron powder is shown in Fig. A1. If the compaction pressure is $p$, the strain $\varepsilon$ is given as

$$
\varepsilon_{\mathrm{p}}=\left(l-l_{\mathrm{p}}\right) / l,
$$

where $l$ and $l_{\mathrm{p}}$ are the thickness of a powder bed before and after compaction. If one assumes that "plastic deformation of particle" takes place after "particle rearrangement," "particle plastic deformation" is given as

$$
\varepsilon_{\mathrm{p}}=\left(l_{\mathrm{ip}}-l_{\mathrm{p}}\right) / l_{\mathrm{ip}},
$$

where $l_{\text {ip }}$ is the thickness of the powder bed at the pressure of $p_{i}$, at which the "particle plastic deformation" starts. Equation (A2) can be replaced by the cross section of the compact parallel to the axis $A^{\prime}$ as

$$
\varepsilon_{\mathrm{p}}=\left(l_{\mathrm{ip}} \cdot A^{\prime}-l_{\mathrm{p}} \cdot A^{\prime}\right) /\left(l_{\mathrm{ip}} \cdot A^{\prime}\right)=\left(V_{\mathrm{ip}}-V_{\mathrm{p}}\right) / V_{\mathrm{ip}} .
$$

where $V_{\mathrm{p}}$ and $V_{\mathrm{ip}}$ are the volumes of the powder bed at pressured $p$ and $p_{\mathrm{i}}$. Equation (A3) is also replaced by weight of the powder bed $w$ as

$$
\varepsilon_{\mathrm{p}}=\left(V_{\mathrm{ip}} / w-V_{\mathrm{p}} / w\right) /\left(V_{\mathrm{ip}} / w\right)=\left(1 / D_{\mathrm{ip}}-1 / D_{\mathrm{G}}\right) /\left(1 / D_{\mathrm{ip}}\right) .
$$

where $D_{\text {ip }}$ is the density of the compact at $p_{\mathrm{i}}$. From the following definition,

$$
\Delta D_{\mathrm{p}}=D_{\mathrm{G}}-D_{\mathrm{ip}},
$$

eq. (5) in 5.1 is given as

$$
\varepsilon_{\mathrm{p}}=\left(D_{\mathrm{G}}-D_{\mathrm{ip}}\right) / D_{\mathrm{G}}=\Delta D_{\mathrm{p}} / D_{\mathrm{G}} .
$$

